\title{
Evolution of genetic variability in a population of the edible snail, Helix aspersa Müller, undergoing domestication and short-term selection
}

\author{
M. DUPONT-NIVET*†, J. MALLARD†, J. C. BONNET§ \& J. M. BLANC \\ $\dagger$ Institut National de la Recherche Agronomique, Laboratoire de Génétique des Poissons, 78352 Jouy en Josas \\ Cedex, France, $\$$ Ecole Nationale Supérieure Agronomique de Rennes, Génétique, 65 rue de St Brieuc, 35042 Rennes \\ Cedex, France, §Institut National de la Recherche Agronomique, Domaine du Magneraud, Héliciculture, BP 52, \\ 17700 Surgères, France and - Institut National de la Recherche Agronomique, Station d'Hydrobiologie, BP 3, 64310 \\ St Pée sur Nivelle, France
}

\begin{abstract}
The evolution of genetic variability is studied in six successive generations of a population originating from wild Helix aspersa. During the first three generations (G1 to G3), no artificial selection was applied. During the next three generations (G4 to G6), two lines were reared: a control line (C) and a line (S) selected for increased adult weight. Genetic variability is described by genealogical parameters (inbreeding, number of founders, effective number of founders and ancestors, effective number of remaining genomes) and by the additive genetic variance in adult weight. A large decrease in all parameters was observed between $G 1$ and $G 2$, suggesting strong natural selection: additive genetic variance in adult weight (transformed data) decreased from $0.0119 \pm 3.8 \times 10^{-3}$ to $0.0070 \pm 1.7 \times 10^{-3}(P<0.05)$ and effective number of ancestors from 97.4 to 67.0. Selection also caused a large decrease during the first generation: additive genetic variance was $0.0079 \pm 2.1 \times 10^{-3}$ in G3 and $0.0040 \pm 1.1 \times 10^{-3}$ after the first selection cycle $(P<0.02)$. At the same time, the effective number of ancestors decreased from 59.2 to 29.5 and 24.2. This decrease is consistent with the theory of selection and the Bulmer effect.
\end{abstract}

Keywords: additive genetic variance, artificial selection, Helix aspersa, natural selection, pedigree, probability of gene origin.

\section{Introduction}

Genetic variability is a prerequisite for selection. Numerous authors have studied its evolution during selection from a theoretical standpoint (for a review, see Walsh \& Lynch, 1998). Results (from simulations or from deterministic models) differ in terms of the magnitude and duration of the period of evolutionary change in genetic variability. Differences depend mainly on the chosen models and the genetic mechanisms that are postulated. However, all agree that the decrease will be large during the first generations of directional selection, because of the establishment of linkage disequilibrium, referred to as the Bulmer effect. The experimental demonstration of the Bulmer effect requires an unselected population. This is a condition hard to fulfil in classical animal species which have been

*Correspondence. E-mail: dnivet@jouy.inra.fr domesticated and selected for a long time. Thus, although the evolution of genetic variability during long-term selection has been extensively studied, a focus on the effect of short-term selection is rare and has concerned laboratory animals such as Drosophila. Helix aspersa is a good new model because, although reared for commercial production, it is still widely present in the wild. This paper aims to use this species to study the evolution of genetic variability during selection (natural or artificial) and, especially, to look for the occurrence of a Bulmer effect. With this objective, data obtained during previous experiments dealing with estimation of genetic parameters and testing the efficiency of selection (Dupont-Nivet et al., 1997a, b, 1998, 2000) were re-analysed. From the dataset, six generations derived from wild founders were available: three generations of domestication with no artificial selection, but possibly natural selection, and three generations with artificial selection for increasing adult weight. The evolution of 
the additive genetic variance of the adult weight was studied. A pedigree analysis (inbreeding and parameters based on probability of gene origin) was also carried out because it gives interesting and complementary information about the evolution of genetic variability.

\section{Materials and methods}

\section{Biological material}

The population studied was reared at INRA, Domaine du Magneraud (France) and was an experimental population consisting of six successive generations (G1 to G6) originating from wild parents (G0). The $\mathrm{G} 1$ to $\mathrm{G} 3$ generations were obtained without intentional selection. But this phase was not free of the possible genetic consequences of domestication, i.e. the adaptation of a wild population to an artificial environment. In G4, two lines were created: one line using mass selection for increasing adult weight, and a control line. These lines were conducted synchronously and continued until G6. The population was completely closed.

\section{Snail biology and rearing}

Rearing methods have been described extensively in Bonnet et al. (1990) and Dupont-Nivet et al. (1997a, b). Only the aspects of biology and rearing essential for understanding the study will be recalled here.

Reproduction. The snail is a protandrous hermaphrodite. Mating occurs between two individuals at the male stage, which fertilize each other. Then both partners turn into females and lay eggs. This is the usual reproduction cycle, but some snails never lay eggs. Pairs where both partners lay eggs are referred to as bilateral and otherwise are referred to as unilateral pairs. In bilateral pairs, the offspring of both partners are full-sibs but the maternal effects are different, thereby allowing us to estimate a reciprocal effect (maternal effects in the broad sense) by comparing clutches within each pair.

For mating, snails were placed into reproduction boxes described in Bonnet et al. (1990). Snails can store sperm from different partners and may lay eggs from several matings in the same brood (Murray, 1964). To avoid multiple matings and to guarantee the reliability of pedigrees, pairs were isolated in egg-laying boxes as soon as they had been observed copulating. This is possible because mating lasts $10-12 \mathrm{~h}$. Preliminary experiments showed that less than $2 \%$ of matings were not observed. When mating was over, snails were separated from one another and given an egg-laying jar. Snails lay eggs several times after mating but only the first time was used here.
Choice of breeding stock. For each generation, the number of breeding stock, reared families and reared animals are reported in Table 1 . No overlapping of generations occurred. The generation length was one year.

G0 wild snails (500) were collected in 1992 at 20 different locations of Poitou-Charentes (France), at a distance of at least $1 \mathrm{~km}$ from each other. Because of this distance, snails from different locations could be considered to be unrelated. For reproduction, snails were allocated into five reproduction boxes (described in Bonnet et al., 1990) such that a minimum number of snails from a same location would be in a same box. This was aimed at minimizing matings between potentially related animals.

For the reproduction of animals of $\mathrm{G} 1$ and $\mathrm{G} 2$, no artificial selection occurred. The breeding stock was randomly sampled from all families (offspring - fullsibs - of a pair constituted a family) to maintain genetic variability. Animals were divided into 15 (G1) or 25 (G2) reproduction boxes with 58 (G1) or 57 (G2) animals per box. Each box contained only one snail from each family to avoid full-sib matings.

For reproduction of G3 to G5, two lines were maintained.

1 A control line (C line): breeding stock was randomly sampled from all families, as for previous generations. At each generation, 120 animals were placed in reproduction boxes. Snails from each family were allocated into two reproduction boxes (60 animals per box) so that matings between full-sibs could be minimized.

2 A selected line (S line): individual selection for increasing adult weight was used. At each generation, the proportion of selected animals was about $13 \%$. At each generation, 240 animals were placed in reproduction boxes. Snails from each family were allocated into four boxes so that matings between full-sibs could be minimized. We deliberately chose to have a larger population in the selected line (see below).

Growth. A snail is considered to be adult when the shell peristome (shell edge) is reflected, i.e. when shell growth is completed.

Because of a lack of room, we could not raise all the clutches and some of them were randomly discarded. Since young snails cannot be shell-tagged, broods could not be mixed. From each clutch, three (G1 and G2) or two (G3 and G4 to G6 of the S line) or one group of 25 snails ( $\mathrm{G} 4$ to $\mathrm{G} 6$ of the $\mathrm{C}$ line), were reared in separate wooden boxes (Bonnet et al., 1990) until adult age. Reared snails were randomly picked out from the whole clutch at the hatching stage. The replicates made it possible to estimate a 'box' effect and therefore to accurately estimate additive genetic variability in G0 to 
G3 and in the selected line. We chose not to estimate genetic variability in the $\mathrm{C}$ line to save enough room for the $\mathrm{S}$ line, because we were more interested in the evolution of additive genetic variability with selection. Thus, in the $\mathrm{C}$ line, there was no replicate of the clutches and only one clutch from bilateral pairs was randomly chosen to be reared. In bilateral pairs of the $\mathrm{S}$ line, snails from clutches of both parents were kept for fattening. This allowed us to include a reciprocal effect in the analysis model and to estimate additive genetic variability more accurately (see statistical analysis below, or Dupont-Nivet et al., 1997b).

The full pedigree (back to G0) of all animals was recorded. G0 founders were considered to be unrelated.

Adult weight was measured for all snails with a Mettler balance (to the nearest $0.01 \mathrm{~g}$ ). The measurements were standardized: snails were picked from the growth boxes as soon as they had become adult and kept in wooden boxes in a dry atmosphere for three days fasting before weighing (Dupont-Nivet et al., 1997a).

\section{Data analysis}

\section{Pedigree analysis}

Genetic structure was analysed on the basis of the pedigree information. An inbreeding coefficient $(F)$ was computed for all the animals, using the Meuwissen \& Luo method (1992).

For each generation, several parameters based on probability of gene origin were also calculated. Any autosomal gene of an individual has a probability 0.5 to come from its dam and a probability 0.5 to come from its sire. Knowing the pedigree, step by step, the probability that a gene originates from a founder animal can be calculated. A founder is an animal without known parents. In our case, since all pedigrees are fully known back to G0, founders are G0 animals. The number of founders, which indicates the exact number of animals from which the population originated, is the first parameter calculated. But founders usually have unbalanced contributions, and an effective number of founders $\left(f_{\mathrm{e}}\right)$ is also computed. It is the theoretical number of founders with balanced contributions which would produce the same genetic diversity as in the studied population. If all founders had equal contributions, $f_{\mathrm{e}}$ would equal the number of founders. However, $f_{\mathrm{e}}$ does not take into account potential bottlenecks. Thus, a number of effective number of ancestors $\left(f_{\mathrm{a}}\right)$ is also computed. An ancestor is an animal, founder or not, which contributes highly to the population studied. Lastly, an effective number of remaining founder genomes $\left(N_{\mathrm{g}}\right)$ is computed which takes into account the random losses of genes during reproduction. It is computed through a Monte-Carlo procedure. Complete details of the calculation of these parameters are given in Boichard et al. (1997).

Inbreeding and other parameters were calculated using FORTRAN programs written by Boichard et al., 1997.

\section{Evolution of additive genetic variability}

The evolution of additive genetic variability for adult weight was studied in G1, G2, G3 and in the S line. For the raw data, there was a nearly significant linear relation between standard deviation and mean $(P=0.06)$. Thus, to render the variance independent of the mean, we used a Keckowski's transformation (Lynch \& Walsh, 1998):

$L P=\log (P+a / b)$

where $L P$ is the new variable, $P$ is the adult weight and $a$ and $b$ are the intercept and the coefficient of the regression of the standard deviation against the mean of the raw data. Here $a / b$ equals 6.15 . After this transformation, there was no more significant linear relation between standard deviation and mean $(P=0.68)$.

For each generation, transformed data were analysed according to the following model:

$L P_{i j k l m}=\mu+U B_{i}+G_{i j}+R_{i j k}+M_{i j k l}+E_{i j k l m}$

where $L P_{i j k l m}$ is the transformed of adult weight of animal $m$ in class $i j k l, \mu$ the overall mean, $U B_{i}$ the fixed effect of the unilateral/bilateral laying-pair $(i=1$ for unilateral pairs, 2 otherwise), $G_{i j}$ the random effect of pair $j, R_{i j k}$ the random reciprocal effect, $M_{i j k l}$ the random effect of the growth box $l$ and $E_{i j k l m}$ the residual error.

This model analysed data from full-sib animals. The pair effect, $G_{i j}$, represents the full-sibs family effect, therefore assuming dominance and epistatic effects to be negligible:

$\sigma_{a}^{2}=2 \sigma_{\mathrm{g}}^{2}$

where $\sigma_{\mathrm{a}}^{2}$ is the additive genetic variance and $\sigma_{\mathrm{g}}^{2}$ is the variance of the pair effect. Thus, heritabilities $\left(h^{2}\right)$ were estimated by:

$h^{2}=2 \sigma_{\mathrm{g}}^{2} / \sigma_{\mathrm{y}}^{2}$,

where $\sigma_{\mathrm{y}}^{2}$ is the phenotypic variance.

To carry out computations, the REML method of the MIXED procedure of SAS (SAS, 1987) was used. Standard

(C) The Genetics Society of Great Britain, Heredity, 87, 129-135. 
errors (SE) were estimated as indicated by Becker (1984).

\section{Results}

For each generation, all the genealogical parameter values are reported in Table 2. The percentage of inbred animals increased with the number of generations, increasing more rapidly in the $\mathrm{S}$ line than in the $\mathrm{C}$ line. In the last generation, all the animals of the $\mathrm{S}$ line and $93 \%$ of the animals of the $\mathrm{C}$ line were inbred. The average $F$ of inbred animals was kept at a low level $(<7 \%)$, but was higher in line $\mathrm{S}(5-6 \%)$ than in line C $(2-4 \%)$. The average $F$ of all animals evolved similarly. The maximum $F$ was high in all generations after G3. This revealed that not all matings between full sibs had been prevented. However, this concerned only $3 \%$ and $9 \%$ of the inbred animals in lines $\mathrm{C}$ and $\mathrm{S}$, respectively. This induced a high variability in $F$, as reflected by the standard error of inbreeding.

The number of founders decreased in G2, remained constant in the control line and slowly decreased in the selected line. The effective number of founders $\left(f_{\mathrm{e}}\right)$ decreased considerably from G1 to G2 (-28.6) and then remained constant until selection. A slight increase $(+5)$ was observed in the first generation of line $\mathrm{C}$, whereas a slight decrease occurred in the following generations. In line $\mathrm{S}$, a large decrease was observed (about $-50 \%$, from G3 to G6-line S), leading to a low effective number of founders (33.2). The difference between number of founders and $f_{\mathrm{e}}$ was always high except in G1. $f_{\mathrm{a}}$ was lower than $f_{\mathrm{e}}$, leading to low $f_{\mathrm{a}}$ in the last generation in both the $\mathrm{C}$ line (34.1) and the $\mathrm{S}$ line (16.8).

Estimates of additive genetic variability and heritability of adult weight are reported in Table 3. Large decreases in additive genetic variability were observed between G1 and G2 (from 0.0119 to $0.0070, F$-test, $P<0.05)$ and after the first generation of selection (from 0.0079 to $0.0040, F$-test, $P<0.02$ ). The evolution of heritability was similar. The evolution of phenotypic variance was also similar, whereas the residual variance was constant.

\section{Discussion}

\section{Completeness and reliability of pedigrees}

All pedigree information was known back to the wild parents, which were considered to be unrelated. The 500 wild parents were collected at 20 locations separated by a distance of at least $1 \mathrm{~km}$. Thus, it is likely that animals from different locations were unrelated, whereas animals from the same location could be related. We could not estimate the level of error since we have no idea of the size or polymorphism level of the populations sampled. Also, information concerning geographical origin of the snails was not kept, so we have no information about differences in reproductive success according to geographical origin and/or mating preferences between snails from the same location. However, the number of matings between snails from the same location was minimized by dividing them into different reproduction boxes.

Two kinds of event can affect the reliability of pedigree information. Incorrect data acquisition should be very rare, since multiple cross-checks of data files were carried out. Multiple matings could have occurred because the snails were grouped in reproduction boxes and withdrawn only after mating. A consequence would be a small underestimation of the genetic variability. Indeed snails can store sperm from several matings and, if some matings are ignored, some parents will be ignored. But, as explained before, mating was controlled to minimize these matings. Preliminary experiments showed that less than $2 \%$ of matings were not observed. Thus, there could not be more than four parents whose

Table 1 Population characteristics for each generation of Helix aspersa

\begin{tabular}{lcccc}
\hline & $\begin{array}{c}\text { Total no. of } \\
\text { animals place } \\
\text { in reproduction }\end{array}$ & $\begin{array}{c}\text { No. of animals } \\
\text { placed in each } \\
\text { reproduction box }\end{array}$ & $\begin{array}{c}\text { No. of parents } \\
\text { for which } \\
\text { offspring are reared }\end{array}$ & $\begin{array}{c}\text { Total no. of reared } \\
\text { offspring present in } \\
\text { the pedigree file } \dagger\end{array}$ \\
\hline G1 & 500 & 100 & 112 & 4150 \\
G2 & 870 & 58 & 136 & 3527 \\
G3 & 1425 & 57 & 152 & 2162 \\
G4, control line & 120 & 60 & 74 & 524 \\
G5, control line & 120 & 60 & 52 & 417 \\
G6, control line & 120 & 60 & 82 & 685 \\
G4, selected line & 240 & 60 & 144 & 3150 \\
G5, selected line & 240 & 60 & 156 & 2694 \\
G6, selected line & 240 & 60 & 132 & 1951 \\
\hline
\end{tabular}

$\dagger$ i.e. which reached adult stage and have recorded performance for adult weight. 


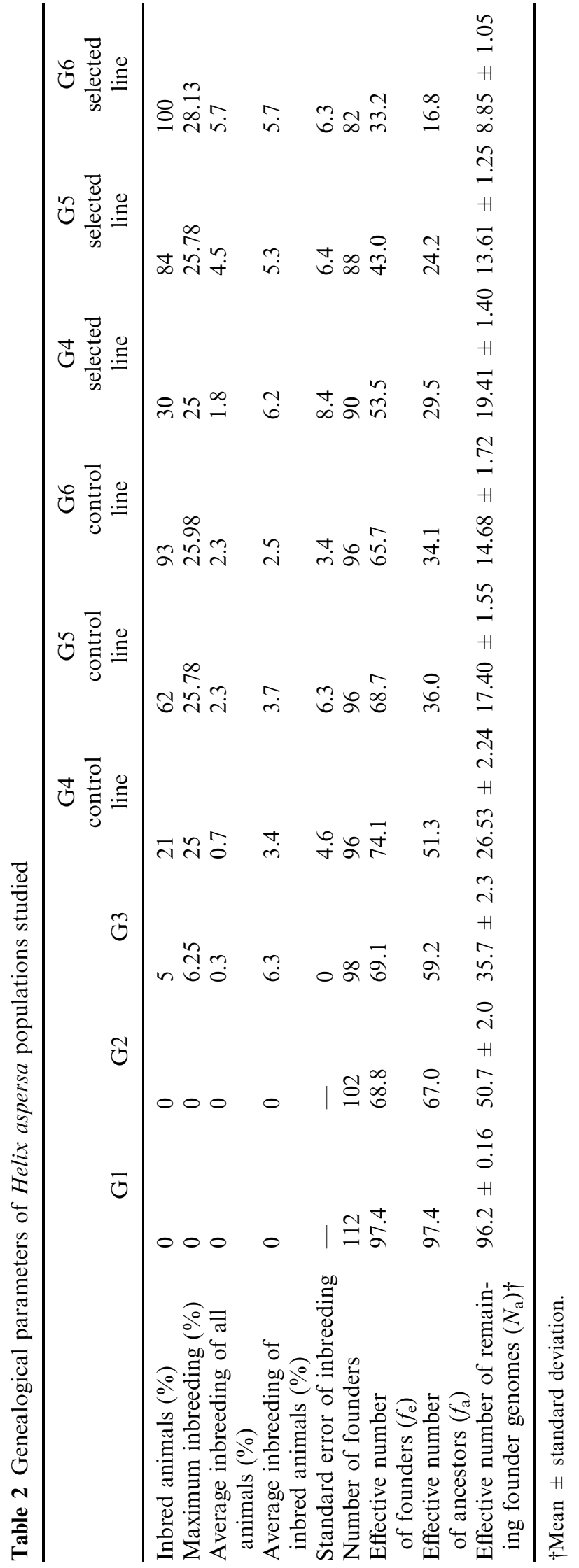

contributions were ignored. The consequences are very likely to be negligible.

\section{Reliability of the estimates of additive genetic variance}

Our estimates of the additive genetic variance could be too high since they are based on covariances between full-sibs. This bias is probably not negligible since we have previously found differences between heritability estimates produced through the covariances between full-sibs and those produced through parent-offspring regression (Dupont-Nivet et al., 1997b). The evolution of dominance variance during selection is difficult to predict and would require much more research. However, its evolution during short-term selection should not be significant and observed changes are likely to be the consequence of changes in the additive genetic variance.

Parallel decreases in phenotypic variability and genetic variance, together with the stability of residual variance, show that the environmental conditions indoors were stable during the experiment. Thus, changes in phenotypic variance are closely linked to changes in genetic variance.

\section{Effect of domestication}

The evolution of inbreeding is commonly observed in studies on the genetic management of animal populations because of its direct effect on performance. Since $\mathrm{G} 0$ animals are considered to be unrelated, inbreeding in G1 was logically zero, but this is probably a small underestimate. An increase in inbreeding occurred only in G3 whereas, in G2, genetic variability had already decreased. This illustrates that inbreeding is a parameter which reflects changes in the management of the population only after a certain time lapse. Moreover, inbreeding estimates are known to be very sensitive to the reliability and completeness of pedigrees. More information can be obtained through parameters based on probability of gene origin.

All parameters derived from probability of gene origin decreased from G1 to G3. The decrease was greater from $\mathrm{G} 1$ to $\mathrm{G} 2\left(-31 \%\right.$ for $\left.f_{\mathrm{a}}\right)$ than from $\mathrm{G} 2$ to G3 $\left(-11 \%\right.$ for $\left.f_{\mathrm{a}}\right)$. The decrease in additive genetic variance, which occurred between G1 and G2, is consistent. These losses of genetic variability could not be attributed to a decrease in population size (Table 1). It is likely that, in the very first generations, strong natural selection against families with low reproductive success or not adapted to artificial rearing occurred. Similarly, Briscoe et al. (1992) showed that, in eight large populations of Drosophila melanogaster, measurements 
Table 3 Evolution of additive genetic variability of $\log ($ adult weight +6.15$)$ during selection (estimate \pm standard errors) in Helix aspersa populations

\begin{tabular}{lcccc}
\hline Generation & Phenotypic variance & Residual variance & Additive genetic variance & Heritability \\
\hline G1 & 0.0172 & $0.0074 \pm 1.7 \times 10^{-4}$ & $0.0119 \pm 3.8 \times 10^{-3}$ & $0.69 \pm 0.22$ \\
G2 & 0.0114 & $0.0066 \pm 1.7 \times 10^{-4}$ & $0.0070 \pm 1.7 \times 10^{-3}$ & $0.61 \pm 0.15$ \\
G3 & 0.0130 & $0.0070 \pm 2.1 \times 10^{-4}$ & $0.0079 \pm 2.1 \times 10^{-3}$ & $0.61 \pm 0.16$ \\
G4, selected line & 0.0104 & $0.0071 \pm 1.9 \times 10^{-4}$ & $0.0040 \pm 1.1 \times 10^{-3}$ & $0.38 \pm 0.11$ \\
G5, selected line & 0.0110 & $0.0074 \pm 2.1 \times 10^{-4}$ & $0.0030 \pm 1.0 \times 10^{-3}$ & $0.27 \pm 0.09$ \\
G6, selected line & 0.0116 & $0.0096 \pm 3.2 \times 10^{-4}$ & $0.0030 \pm 7.5 \times 10^{-4}$ & $0.26 \pm 0.06$ \\
\hline
\end{tabular}

of genetic variation (allozyme heterozygosities, additive genetic variances and heritabilities for sternopleural bristle number) declined over time in captivity.

In the $\mathrm{C}$ line, large decreases in $f_{\mathrm{a}}$ and $N_{\mathrm{g}}$ between $\mathrm{G} 4$ and $\mathrm{G} 5$ are mainly explained by the reduction in the line size from 37 families to 26 . Other decreases (between G2 and G3 and in the control line) in genealogical parameter values can be explained by differences in the reproductive success of animals, i.e. their ability to mate (some snails did not mate and had no offspring) and by the random elimination of clutches because there was not enough room to rear them all.

\section{Effect of selection}

The decrease in the genealogical parameters was greater in the $\mathrm{S}$ line than in the $\mathrm{C}$ line even though there were more families in the former. The number of founders shows that losses of initial G0 genetic origins occurred in the $\mathrm{S}$ line but not in the $\mathrm{C}$ line. Differences between number of founders and $f_{\mathrm{e}}$ and between $f_{\mathrm{e}}$ and $f_{\mathrm{a}}$ were greater in the $\mathrm{S}$ line, revealing more unbalanced contributions of founders, and more bottlenecks, than in the $\mathrm{C}$ line. A greater decrease in $N_{\mathrm{g}}$ in the $\mathrm{S}$ line shows that random drift was greater under selection. It is difficult to compare our population with studies found in the literature because the species studied (cattle, pigs, rabbits) are very different and have very different biological and population management constraints.

Losses of genetic variability were also revealed by the decrease in additive genetic variance. The observed losses of genetic variability are consistent with theoretical work (analytical or simulation). Three effects can affect genetic variability. The first is the occurrence of linkage disequilibrium, which can lead to a considerable decrease of additive genetic variability during the first cycles of selection (Lush, 1948; Bulmer, 1971). After a few generations, this effect is expected not to influence genetic variability any further because recombinations compensate for losses due to linkage disequilibrium. Secondly, changes in gene frequencies could make the genetic variability decrease, but this effect is considered to be negligible under an infinitesimal model (Verrier et al., 1990). Finally, the enhancement of random drift could affect the genetic variability. Indeed, under selection, two animals of the same family have a greater probability of both being rejected or both being selected than two animals taken at random (Robertson, 1961). This is consistent with the evolution of genealogical parameters in the $\mathrm{S}$ line, especially the higher occurrence of bottlenecks and the greater decrease in $N_{\mathrm{g}}$ (which reveals a higher random drift).

All indicators of genetic variability lead to the same conclusion: rapid decrease of genetic variability during the first cycles of selection (natural or artificial). However, it must be said that evolution of genetic response is surprising. Indeed, genetic response (calculated as the ratio $100 \times$ (mean of selected line - mean of control line)/mean of control line) was constant (11.4-11.7\%) over the three selection generations. Realized heritability was also constant (39\%) (Dupont-Nivet et al., 2000). But, if additive genetic variability decreases, genetic response should decrease also. This is probably explained by the positive genetic correlation between the egg-layer's weight and the egg weight (0.33, DupontNivet et al., 1998) which can speed up the response to selection. The evaluation of genetic response for the male pathway alone should be useful to resolve this issue.

Many experiments have studied losses of genetic variability during long-term selection (Rasmuson, 1964; Bell \& Burris, 1973; Yoo, 1980; Douaire, 1982; Gallego \& Lopez-Fanjul, 1983) but few have concerned shortterm selection experiments. Sorensen \& Hill (1982) studied short-term evolution in two lines of Drosophila melanogaster selected for abdominal bristle number. In one line, genotypic variance was found to increase slightly, whereas in the other line it tended to decline. Their interpretation, supported by simulation results, is that a decline in genetic variance should be expected under an infinitesimal model but not if major genes are involved.

Studies of decreased genetic variability during shortterm selection experiments are seldom carried out, because populations must be large enough to estimate 
genetic variability for each generation and because unselected populations are required, which is almost impossible for domestic animal species. The originality of our work is that our G3 population was very close to a true base population for selection. Indeed, though it was not totally free from inbreeding, it was not selected, could be considered to be close to genetic equilibrium and matings were panmictic (Dupont-Nivet et al., 1997a).

\section{Conclusion}

As predicted by Bulmer (1971) and many authors after him, rapid losses of genetic variability (genealogical parameters and additive genetic variability) were observed in our population undergoing early domestication and selection.

\section{Acknowledgements}

We would like to express our appreciation to Messrs $\mathbf{J}$. Gautier, C. Finociety and H. Rouet for their help in rearing the animals. This work was funded by the INRA and the Conseil Régional de Poitou-Charentes. We also thank the Animal Genetics Department of INRA which allowed us access to their computing facilities and D. Boichard who made his program available to us. We are very grateful to Mr de Rochambeau, Mrs V. Kerdiles, $\mathrm{Mr}$ E. Verrier, the Fish Genetics Unit and two referees for helpful and stimulating discussions. The English was kindly revised by the Translation Unit of the INRA.

\section{References}

BECKER, w. A. 1984. Manual of Quantitative Genetics, 4th edn. Academic Enterprises, Pullman, WA.

BELL, A. E. AND BURRIS, M. A. 1973. Simultaneous selection for two correlated traits in Tribolium. Genet. Res., 21, 29-46.

BOICHARD, D., MAIGNEL, L. AND VERRIER, E. 1997. The value of using probabilities of gene origin to measure genetic variability in a population. Génét. Sél. Évol., 29, 5-23.

BONNET, J. C., AUPINEL, P. AND VRILLON, J. L. 1990. L'escargot Helix aspersa, biologie, élevage. INRA Ed., Versailles.

BRISCOE, D. A., MALPICA, J. M., ROBERTSON, A., SMITH, G. J. ET $A L$. 1992. Rapid loss of genetic variation in large captive populations of Drosophila flies: implications for the genetic management of captive populations. Conserv. Biol., 6, 416-425.
BULMER, M. G. 1971. The effect of selection on genetic variability. Am. Nat., 105, 201-211.

DOUAIRE, M. 1982. Evolution de la variabilité génétique en sélection. PhD Thesis Université Pierre et Marie Curie Paris VI.

DUPONT-NIVET, M., GUILlER, A. AND BONNET, J. C. 1997a. Genetic and environmental variability of adult size in some stocks of the edible snail, Helix aspersa Müller. J. Zool. Lond., 241, 757-765.

DUPONT-NIVET, M., MALLARD, J., BONNET, J. C. AND BLANC, J. M. 1997b. Quantitative genetics of growth traits in the edible snail, Helix aspersa Müller. Génét. Sél. Évol., 29, 571-587.

DUPONT-NIVET, M., MALLARD, J., BONNET, J. C. AND BLANC, J. M. 1998. Quantitative genetics of reproductive traits in the edible snail, Helix aspersa Müller. J. Exp. Zool., 281, 220-227.

DUPONT-NIVET, M., MALLARD, J., BONNET, J. C. AND BLANC, J. M. 2000. Direct and correlated responses to individual selection for large adult weight in the edible snail, Helix aspersa Müller. J. Exp. Zool., 287, 80-85.

GALlEGO, A. AND LOPEZ-FANJUL, C. 1983. The number of loci affecting a quantitative trait in Drosophila melanogaster revealed by artificial selection. Genet. Res., 42, 137-149.

Lush, J. L. 1948. The Genetics of Populations. Original and Revised Notes (1948-94). Iowa State University Press.

LYNCH, M. AND WALSH, B. 1998. Genetics and Analysis of Quantitative Traits. Sinauer, Sunderland, MA.

MEUWISSEN, T. H. E. AND LUO, Z. 1992. Computing inbreeding coefficients in large populations. Génét. Sél. Évol., 24, 305-313.

MURRAY, J. 1964. Multiple mating and effective population size in Cepaea nemoralis. Evolution, 18, 283-291.

RASMUSON, M. 1964. Combined selection for two bristle characters in Drosophila. Hereditas, 51, 231-256.

ROBERTSON, A. 1961. Inbreeding in artificial selection programmes. Genet. Res., 2, 189-194.

SAS, 1987. User's Guide: Statistics, Version, 6, vols 1 and 2. SAS Institute, Cary, NC.

SORENSEN, D. A. AND HILL, W. G. 1982. Effect of short term directional selection on genetic variability: experiments with Drosophila melanogaster. Heredity, 48, 27-33.

VERRIER, E., COLlEAU, J. J. AND FOULlEY, J. L. 1990. Predicting cumulated response to directional selection in finite panmictic populations. Theor. Appl. Genet., 79, 833-840.

WALSH, B. AND LYNCH, M. 1998. Vol. 2: Evolution and Selection of Quantitative Traits. http://nitro.biosci.arizona.edu/zbook/ volume_2/vol2.html.

YoO, в. H. 1980. Long-term selection for a quantitative character in large replicate populations of Drosophila melanogaster. Part 3. The nature of residual variability. Theor. Appl. Genet., 57, 27-32. 